\title{
Application of preoperative embolization during surgery for the destroyed lung
}

\author{
Yi-Ming Zhou ${ }^{1}$, Nan Song ${ }^{1}$, Lei Lin ${ }^{1}$, Ge-Ning Jiang ${ }^{1}$, Sen Jiang ${ }^{2}$ \\ ${ }^{1}$ Department of Thoracic Surgery, ${ }^{2}$ Department of Radiology, Shanghai Pulmonary Hospital, Tongji University, School of Medicine, Shanghai \\ 200433, China \\ Contributions: (I) Conception and design: YM Zhou, S Jiang; (II) Administrative support: S Jiang; (III) Provision of study materials: All authors; (IV) \\ Collection and assembly of data: YM Zhou, N Song, L Lin, GN Jiang; (V) Data analysis and interpretation: YM Zhou; (VI) Manuscript writing: All \\ authors; (VII) Final approval of the manuscript: All authors. \\ Correspondence to: Sen Jiang. Department of Radiology, Shanghai Pulmonary Hospital, Tongji University, School of Medicine, No. 507, Zhengmin \\ Road, Shanghai 200433, China. Email: jasfly77@vip.163.com.
}

\begin{abstract}
Background: The destroyed lung has been a challenge in the clinical practice of thoracic surgery, and severe adhesions and massive bleeding during surgery are the main obstacles faced by surgeons. This study aimed to investigate the efficacy of the preoperative embolization of blood vessels in adhesions during surgery for the destroyed lung.
\end{abstract}

Methods: A total of 7 patients underwent preoperative embolization for lung resection of destroyed lungs between June 2016 and February 2019. Preoperative embolization was performed for 45 min to $2 \mathrm{~h}$ within $48 \mathrm{~h}$ before surgery. The embolized arteries included the intercostal artery, radial artery, subclavian artery and their branches, and the number of embolized arteries ranged from 5 to 13 .

Results: A posterolateral incision was made in these patients, and endoscope-assisted separation of the adhesions at the top of the chest wall and on the lateral chest wall was performed. The operation time ranged from 3.5 to $8 \mathrm{~h}$, and the blood loss was 1,200-5,000 $\mathrm{mL}$. The postoperative drainage was in the normal range. One patient developed multiple organ failure and bronchopleural fistulas (BPF) one month after surgery, which was resolved after active drainage and argon cauterization; another patient developed BPF 7 months after surgery, which was resolved after placement of a nonreturn valve in the subsegmental bronchi via bronchoscopy.

Conclusions: Surgery of the destroyed lung is a great challenge in clinical practice, mainly due to the risk of the blood supply in the adhesions. Preoperative embolization may reduce intraoperative blood loss and surgical difficulty.

Keywords: Destroyed lung; surgery; embolization

Submitted Jul 17, 2019. Accepted for publication Feb 11, 2020.

doi: 10.21037/apm.2020.04.02

View this article at: http://dx.doi.org/10.21037/apm.2020.04.02

\section{Introduction}

The destroyed lung often occurs as a result of long-lasting lung infection, especially pulmonary tuberculosis. Patients with destroyed lungs who develop aspergilloma usually present with hemoptysis, and interventional embolization of the bronchial artery is a temporary treatment for the control of bleeding under this condition $(1,2)$. However, surgical intervention is the ultimate treatment for the destroyed lung (3-6). Notably, pneumonectomy of the destroyed lung has been a challenge in clinical practice, mainly due to the presence of intraoperative adhesions, bleeding as a result of adhesion separation, the incarceration and calcification of lymph nodes in the hilar and portal areas and changes in the anatomical location of the lung due to a mediastinal 
shift. In addition, there is a high incidence of postoperative complications after surgery in these patients (7). Thus, the control of intraoperative risks is of great importance for the reduction of postoperative complications and favorable prognosis $(8,9)$. Thus, intraoperative adhesions and bleeding have been obstacles during pneumonectomy of the destroyed lung $(7,9,10)$. The present study aimed to investigate the role of preoperative embolization during pneumonectomy of the destroyed lung.

\section{Methods}

A total of 7 patients underwent lung resection for destroyed lungs between June 2016 and February 2019. They were all males, and the mean age was $50.8 \pm 7.1$ years (range, $32-71$ years). Five patients underwent prior interventional embolization for repeated massive hemoptysis, of whom 1 developed Aspergillus recurrence after right upper lobectomy. All these patients had no hemoptysis within 3 months before surgery. After admission, cardiac and lung functions were assessed, and bronchoscopy was performed. As shown in Table 1, all the patients underwent preoperative embolization within $48 \mathrm{~h}$ before surgery. Embolization involved the whole affected lung. Preoperative embolization was not confined to the bronchial arteries in the lesion, and the intercostal artery and the collateral arteries in the systemic circulation in the lesion were also embolized if necessary. The materials used for embolization included coils and gelatin sponges. The embolization time ranged from $45 \mathrm{~min}$ to $2 \mathrm{~h}$, and the number of arteries embolized ranged from 5 to 13 . The embolized arteries included the bronchial arteries, intercostal artery, internal thoracic artery, lateral thoracic artery, infraorbital artery, esophageal artery, and subscapular artery.

\section{Results}

There were no complications after interventional therapy, and all the patients underwent endoscopeassisted separation of the adhesions at the top of the chest well and on the lateral chest wall within $48 \mathrm{~h}$ after embolization. The operation time ranged from 3.5 to $8 \mathrm{~h}$ (mean: $5.8 \pm 1.8 \mathrm{~h}$ ), dense adhesions were noted in all the patients, and blood loss ranged from 1,200 to $5,000 \mathrm{~mL}$ (mean: 2,600 $1,700 \mathrm{~mL}$ ). The thoracic tube indwelling time was 5-28 days (mean: $13 \pm 9$ days). The intercostal muscle or anterior serratus muscle was separated during the thoracotomy as the muscle flap to cover the bronchial stump at the end of surgery. Patients with Aspergillus infection received anti-fungal therapy for 2-3 months. One patient (case 3) developed multiple organ failure and then bronchopleural fistulas (BPF) 1 month after surgery, which was resolved after drainage and bronchoscope-assisted argon cauterization; another 2 patients (case 5 and case 7) developed prolonged air leakage, which was resolved after drainage, but both had a residual cavity at the top of the thoracic cavity. Case 5 also developed BPF 7 months after surgery, and drainage was then employed. CT and bronchoscopy showed the fistula at the dorsal subsegmental bronchus of the lower lung, which was nonresponsive to repeated cauterization. Finally, the patient recovered after the endobronchial valve (Zephyr 4.0, PulmonX) was placed in the subsegment with the aid of a bronchoscope. Followup showed no sign of thoracic infection. The remaining 5 patients had no major complications and were discharged. Follow-up revealed that the quality of life was good in these patients.

\section{Discussion}

Interventional embolization is an effective, temporary treatment for massive hemoptysis as a result of the destroyed lung, but recurrence is common $(2,5)$. For patients with infection-related destroyed lungs, especially those with concomitant massive hemoptysis, pneumonectomy is the ultimate treatment (1,3-8). However, pneumonectomy of the destroyed lung is a great challenge in clinical practice and has a high incidence of postoperative complications. However, postoperative complications are closely related to the prognosis of these patients $(7,8)$, and blood loss has been found to be an independent risk factor for postoperative complications (7). Preoperative embolization was first introduced in patients receiving surgery for mediastinal tumors, aiming to reduce intraoperative blood loss, which has been confirmed in some studies (11-13). Thus, this study was undertaken to investigate the role of preoperative embolization during surgery for the destroyed lung. In the present study, embolization was performed within 48 h before surgery, patients had no symptoms of hemoptysis upon embolization, and the extent of embolization was enlarged, which was different from previous reports (9). Careful embolization of the arteries in the systemic circulation was performed at the thoracic index, aiming to avoid interference with the blood supply to the spinal cord. Moreover, careful separation of adhesions at the thoracic index, even after embolization, was also performed. When 


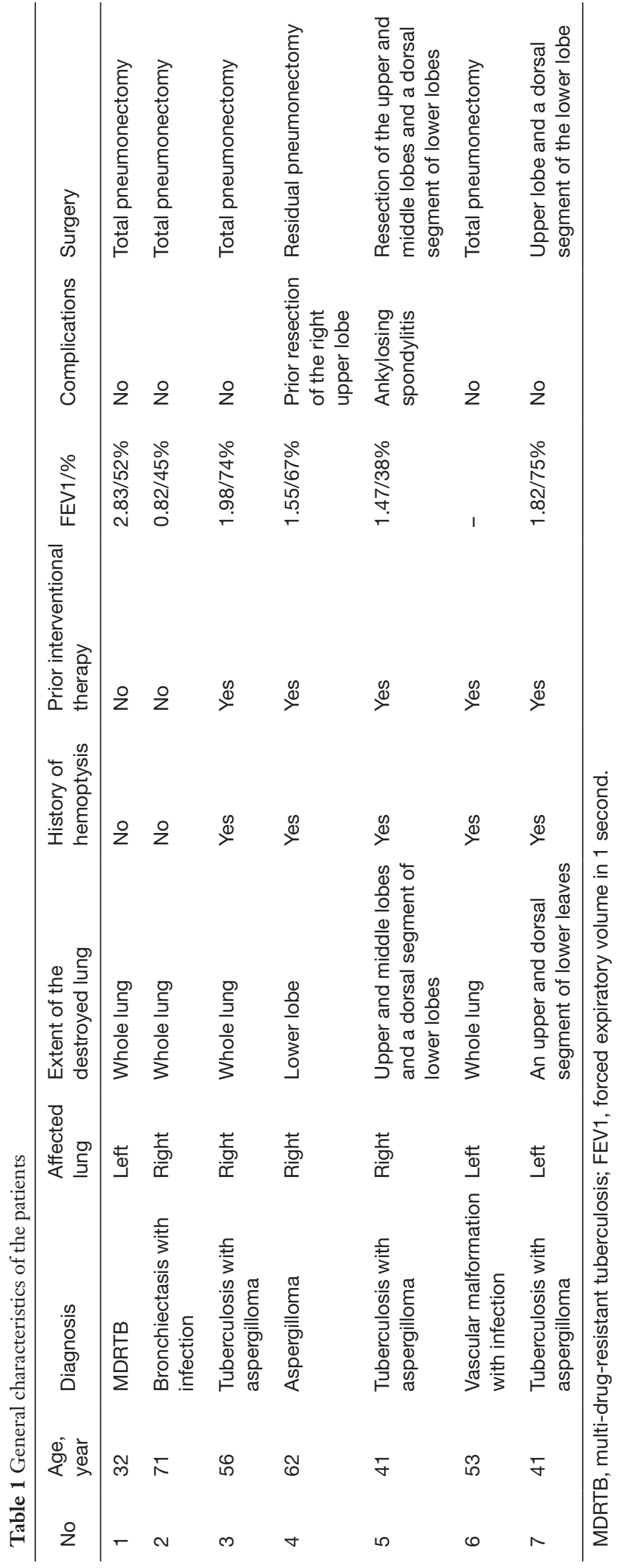

close to the thoracic index, the lung tissue was carefully cut open, the aspergilloma was carefully removed, avoiding contamination of the surrounding tissues, and a small portion of the adherent lung tissues at the thoracic index remained intact. After surgery, the surgical site was flushed repeatedly, and antifungal therapy was then initiated. Dissection of the dense adhesions near the thoracic index can be very dangerous; it has the risk of damaging the subclavian vessels or brachial plexus, which would be catastrophic. In the present study, there was a small portion of lung tissue left near the thoracic index in all 7 patients. The blood loss ranged from 1,200 to $5,000 \mathrm{~mL}$. This was a retrospective study, and thus, there was no control group in our study. In addition, the sample size was small, and the degree of adhesions varied in these patients with destroyed lungs, as it is difficult to conduct prospective, randomized, controlled studies. However, compared to our experience in clinical practice, there tended to be decreased blood loss in these patients. For patients receiving this surgery, BPF is a major complication. Although the bronchial stump was covered with the muscle, 2 patients still developed BPF. In case 3, the fluctuation of blood pressure during the surgery caused long-term insufficient perfusion, resulting in multiple organ dysfunction and BPF one month after surgery. However, the fistula recovered smoothly after bronchoscope-assisted treatment. There was a history of ankylosing spondylitis in case 5 , and he was intolerant to total pneumonectomy due to poor lung function. Thus, the basal segment of the right lower lung remained, and the dorsal bronchus was cut with a stapler along the dorsal border due to lymph node incarceration in the portal area. Thus, the bronchial stump was relatively long, which was a risk factor for fistula formation. Once a fistula formed during the late stage, an endobronchial valve was finally placed into this segment because of the long bronchial stump. This patient was followed for 12 months, and no signs of infection were observed.

\section{Conclusions}

Surgery of the destroyed lung has been a great challenge in clinical practice, mainly due to the presence of adhesions rich in blood supply and the high incidence of postoperative complications related to intraoperative blood loss. Based on our findings, preoperative embolization is a safe treatment in the preoperative preparation for surgery of the destroyed lung. Preoperative embolization can reduce intraoperative blood loss and decrease surgical difficulty. Although evidence 
from prospective, randomized, controlled studies is lacking, embolization before surgery for destroyed lungs is a strategy worth attempting in order to reduce intraoperative blood loss.

\section{Acknowledgments}

Funding: None.

\section{Footnote}

Conflicts of Interest: All authors have completed the ICMJE uniform disclosure form (available at http://dx.doi. org/10.21037/apm.2020.04.02). The authors have no conflicts of interest to declare.

Ethical Statement: The authors are accountable for all aspects of the work in ensuring that questions related to the accuracy or integrity of any part of the work are appropriately investigated and resolved. This study was approved by the Ethics Committee of our hospital (K20001). Written informed consent was obtained from the patient for publication of this manuscript and any accompanying images.

Open Access Statement: This is an Open Access article distributed in accordance with the Creative Commons Attribution-NonCommercial-NoDerivs 4.0 International License (CC BY-NC-ND 4.0), which permits the noncommercial replication and distribution of the article with the strict proviso that no changes or edits are made and the original work is properly cited (including links to both the formal publication through the relevant DOI and the license). See: https://creativecommons.org/licenses/by-nc-nd/4.0/.

\section{References}

1. Yoon W, Kim JK, Kim YH, et al. Bronchial and nonbronchial systemic artery embolization for lifethreatening hemoptysis: a comprehensive review. Radiographics 2002;22:1395-409.

Cite this article as: Zhou YM, Song N, Lin L, Jiang GN, Jiang S. Application of preoperative embolization during surgery for the destroyed lung. Ann Palliat Med 2020;9(3):644-647. doi: 10.21037/apm.2020.04.02
2. Gupta A, Sands M, Chauhan NR. Massive hemoptysis in pulmonary infections: bronchial artery embolization. J Thorac Dis 2018;10:S3458-64.

3. Issoufou I, Sani R, Belliraj L, et al. Pneumonectomy for tuberculosis destroyed lung: A series of 26 operated cases. Rev Pneumol Clin 2016;72:288-92.

4. Kendja F, Tanauh Y, Kouame J, et al. Surgical management of lungs destroyed by tuberculosis. Rev Pneumol Clin 2006;62:171-4.

5. Alexander GR. A retrospective review comparing the treatment outcomes of emergency lung resection for massive haemoptysis with and without preoperative bronchial artery embolization. Eur J Cardiothorac Surg 2014:45:251-5.

6. Patel R, Singh A, Mathur RM, et al. Emergency pneumonectomy: a life-saving measure for severe recurrent hemoptysis in tuberculosis cavitary lesion. Case Rep Pulmonol 2015;2015:897896.

7. Li Y, Hu X, Jiang G, et al. Pneumonectomy for Treatment of Destroyed Lung: A Retrospective Study of 137 Patients. Thorac Cardiovasc Surg 2017;65:528-34.

8. Shiraishi Y, Katsuragi N, Nakajima Y, et al. Pneumonectomy for complex aspergilloma: is it still dangerous? Eur J Cardiothorac Surg 2006;29:9-13.

9. Chen G, Zhong FM, Xu XD, et al. Efficacy of regional arterial embolization before pleuropulmonary resection in 32 patients with tuberculosis-destroyed lung. BMC Pulm Med 2018;18:156.

10. Halezeroglu S, Okur E. Thoracic surgery for haemoptysis in the context of tuberculosis: what is the best management approach? J Thorac Dis 2014;6:182-5.

11. Zhou Y, Chen C, Bao M, et al. Preoperative embolization followed by surgical excision of a giant thymic carcinoid. Interact Cardiovasc Thorac Surg 2013;16:541-3.

12. Puma F, Cardini CL, Passalacqua G, et al. Preoperative embolization in surgical management of giant thoracic sarcomas. Eur J Cardiothorac Surg 2008;33:127-9.

13. Khairy M, Othman MH, Ali EM, et al. Preoperative embolization in surgical management of massive thoracic tumors. Asian Cardiovasc Thorac Ann 2012;20:689-93. 